\title{
"YESUS SEBAGAI PENGGENAP TEMPAT IBADAH" DALAM INJIL YOHANES
}

\author{
Stefanus Kristianto
}

\begin{abstract}
Abstrak: Salah satu karakteristik yang kerap muncul dalam Injil Yohanes ialah menampilkan Yesus sebagai penggenap ritual, figur, atau nubuatan dalam Perjanjian Lama. Bertolak dari dasar itu, tulisan ini akan mencoba berfokus pada bagaimana Injil Yohanes menampilkan Yesus sebagai penggenap tempat ibadah di dalam Perjanjian Lama. Untuk mencapai tujuan itu, penulis akan mulai dengan menunjukkan bahwa Perjanjian Lama merupakan latar belakang konseptual di balik Injil Yohanes. Setelah itu, penulis akan meneliti perkembangan konseptual tempat ibadah di dalam Perjanjian Lama untuk mengetahui aspek apa saja yang digenapi dan bagaimana Yesus menggenapinya. Pada akhirnya, penulis akan menarik beberapa implikasi praktis penggenapan tersebut bagi kehidupan Kristen kontemporer.
\end{abstract}

Kata Kunci: Yesus, Perjanjian Lama, Injil Yohanes, Penggenapan, Tempat Ibadah.

\begin{abstract}
One characteristic that frequently appears in the Gospel of John is to perform Jesus as the fulfilment of rites, figures, or prophecies in the Old Testament. Starting from that basis, this paper will try to focus on how the Gospel of John presents Jesus as the fulfilment of the place of worship in the Old Testament. To achieve that goal, the author will start by pointing out that the Old Testament is the conceptual background behind the Gospel of John. After that, the author will examine the conceptual development of the place of worship in the Old Testament, in order to find out what aspects are fulfilled and how Jesus fulfilled them. In the end, the author will draw some practical implications of that fulfilment for the contemporary Christian life.
\end{abstract}

Keywords: Jesus, the Old Testament, the Gospel of John , Fulfilment, Place of Worship 


\section{PENDAHULUAN}

Di dalam kehidupan beragama bangsa Israel, tempat ibadah tentu saja memainkan peran yang amat sentral. Bagi mereka, tempat ibadah merupakan lambang kehadiran Tuhan di tengah-tengah mereka. Di dalam tulisan ini, penulis akan mencoba menunjukkan wacana baru yang diungkapkan Injil Yohanes mengenai tempat ibadah, tepatnya bagaimana penulis Injil ini menampilkan Yesus sebagai penggenapan tempat ibadah di dalam Perjanjian Lama.

Dalam mencapai tujuan tersebut, pertama-tama penulis akan memaparkan latar belakang konseptual Injil Yohanes. Hal ini penting dilakukan untuk menunjukkan bahwa Yohanes memang sedang mengaitkan Yesus dengan Perjanjian Lama, dan bukan dengan konsep lainnya. Beberapa sarjana menganggap bahwa latar belakang konseptual Injil Yohanes adalah filsafat dualisme Yunani atau sejenisnya. Bila ini benar, maka argumen penulis bahwa Injil Yohanes menampilkan Yesus sebagai penggenap konsep tempat ibadah dalam Perjanjian Lama dengan sendirinya akan runtuh. Namun bila yang benar sebaliknya - bahwa latar belakang konseptual Injil Yohanes adalah tulisan Yahudi, termasuk juga Perjanjian Lama - maka tindakan penulis mengaitkan Injil Yohanes dengan Perjanjian Lama adalah tindakan yang valid. ${ }^{1}$

Penulis kemudian akan menguraikan sketsa perkembangan konsep tempat ibadah di dalam Perjanjian Lama untuk memperjelas aspek apa saja yang nanti akan digenapi oleh Yesus. Setelah itu, penulis akan menjelaskan bagaimana Yohanes menampilkan Yesus sebagai penggenap tempat ibadah di dalam Perjanjian Lama, sebelum akhirnya penulis akan menarik beberapa implikasi praktis penggenapan tersebut bagi kehidupan Kristen kontemporer.

\footnotetext{
Karena penulis membatasi diri hanya pada upaya Yohanes menampilkan Yesus sebagai penggenap tempat ibadah, maka pertanyaan krusial lain tidak akan dibahas di sini. Termasuk perkembangan konsep di dalam Yudaisme sendiri, yang setelah penghancuran Bait Allah pada tahun $70 \mathrm{M}$ oleh Titus Vespasianus, tidak lagi berupaya membangun Bait Allah, melainkan memilih untuk beribadah di sinagoga.
} 


\section{LATAR BELAKANG KONSEPTUAL INJIL YOHANES}

Pada awalnya, mayoritas sarjana Perjanjian Baru (mis. Bultmann, Haenchen, Dodd, Barret) cenderung melihat Injil Yohanes sebagai Injil yang sangat helenis. Berbagai usulan mereka nominasikan untuk menjadi latar belakang konseptual Injil ini, mulai dari Gnostisisme, Hermetica, filsafat Philo, Hellenistik Yahudi, dan berbagai wawasan dunia helenis lainnya. Konsep $\lambda o ́ \gamma o \varsigma$ dan dualisme (terang-gelap, atas-bawah, dan sebagainya) dianggap para sarjana tersebut sebagai rujukan eksplisit kepada filsafat Yunani. ${ }^{2}$

Akan tetapi, kini mayoritas sarjana lebih sepakat bahwa latar belakang konseptual Injil Yohanes ialah kultur dan tradisi religi Yahudi. Salah satu alasan mengapa para sarjana mulai meninggalkan anggapan bahwa Injil Yohanes dipengaruhi oleh filsafat Yunani ialah karena dangkalnya kesamaan yang diajukan antara Injil Yohanes dan tulisantulisan filsafat Yunani tersebut. Carson menyatakan,

"Words like light, darkness, life, death, spirit, word, love, believing, water, bread, clean, birth, children of God, can be found in almost any religion into which one probes. Frequently, they have diferent referents as one moves from religion to religion, but the vocabulary is as popular as religion itself.",

Di sini, Carson mengingatkan bahaya sikap yang disebut Samuel Sandmell sebagai "parallelomania," yakni mengemukakan paralelparalel yang arti pentingnya sebenarnya diragukan. ${ }^{5}$

\footnotetext{
Yakub Tri Handoko, Diktat Kuliah Injil Yohanes (Pacet: STTIAA, 2005), h.9.

D.A. Carson, The Gospel Accoding to John (PNTC; Grand Rapids: Eerdmans, 1991), p.59.

5 Samuel Sandmel, "Parallelomania," JBL 81 (1962): 2-13; untuk penjelasan singkatnya lihat D.A. Carson, Kesalahan-Kesalahan Eksegetis (trans. Lanna Wahyuni; Surabaya: Momentum, 2009), h.48-9.
}

4 Ibid. 
Penemuan Naskah Laut Mati juga menyadarkan para sarjana bahwa penggunaan bahasa dualistik dalam Injil Yohanes bisa berakar dalam tulisan Yahudi, dan tidak harus dikaitkan dengan filsafat Yunani. Itu sebabnya Carson mengatakan, "the 'new look' prompted by the discovery of the Dead Sea Scrolls has forced all but the most enthusiastic supporters of hellenistic influence to pause." Selain itu, pembacaan yang menyeluruh terhadap Injil Yohanes menunjukkan bahwa nosi Yohanes berpijak pada Perjanjian Lama sebagai stand-point sudah sangat konklusif. ${ }^{6}$ Sebab itu, kesimpulannya - seperti yang diungkapkan Carson - ialah,

"The fundamentally Jewish and Old Testament background to John's Gospel is increasingly recognized. What we call the Old Testament is what he repeatedly quotes, and that to which he repeatedly and explicitly alludes ... And the dominant influences, the things that constrain his thought and theology, are the Old Testament, the heritage of Judaism, his knowledge both of firstcentury Palestine and of the culture and heritage of those for whom he is writing, and above all his grasp of the person, ministry and work of Jesus the Messiah, and the Christian understanding that was mediated to him through the work of the Spirit in the life of the church.",

\section{SKETSA PERKEMBANGAN TEMPAT IBADAH DI DALAM PERJANJIAN LAMA}

Di dalam Perjanjian Lama, setidaknya ada tiga fase utama yang menandai perkembangan konsep tempat ibadah bangsa Israel, yakni fase pra-Mosaik yang merupakan fase paling sederhana, fase Mosaik sampai Davidik yang semi-permanen, dan fase Davidik hingga PaskaPembuangan yang jauh lebih stabil.

\footnotetext{
6 Untuk argumen-argumen yang mendukung nosi ini, lihat Handoko, Injil Yohanes, h.10-1.

7 Carson, John, pp. 59-60, 63.
} 


\section{Fase Pra-Mosaik}

Di dalam masa ini, terlihat jelas belum adanya sentralisasi tempat ibadah. Beberapa tokoh yang beribadah - baik dengan cara mendirikan mezbah dan/atau mempersembahkan korban ${ }^{8}$ - melakukannya di tempattempat yang sporadis. Tempat Kain dan Habel mempersembahkan korban di Kejadian 4 nampaknya tidak sama dengan tempat Nuh mempersembahkan korbannya di Kejadian 8, yang kemungkinan terjadi di sekitar gunung Ararat (8:4). Di dalam catatan kisah Abraham, bisa ditemukan bahwa ia beberapa kali mendirikan mezbah di tempat-tempat yang berbeda, misalnya di suatu tempat dekat Sikhem (Kejadian 12:6-7), di Betel dan Ai (Kejadian 12:8; 13:3-4), ${ }^{9}$ serta di gunung Moria ketika ia hendak mempersembahkan Ishak (Kejadian 22:9).

Ishak tercatat satu kali mendirikan mezbah bagi Tuhan di Bersyeba (Kejadian 26:25), sedangkan Yakub tercatat beberapa kali mempersembahkan korban maupun mendirikan mezbah, di antaranya satu kali mempersembahkan korban di pegunungan Gilead (Kejadian 31:54) serta dua kali mendirikan mezbah yaitu di Sikhem (Kejadian

8 Wenham menulis, "Sacrifice was the normal mode of worship in the OT ... Both building an altar and offering sacrifice were expressions of faith in the promise and were integral to the worship of God." [Gordon J. Wenham, Genesis 1-15 (WBC; Dallas: Word, 1987), 280].

9 Sailhamer mencatat bahwa bukan kebetulan tiga tempat ini (Sikhem, Betel, dan Ai) merupakan tempat yang sama yang dikunjungi Yakub ketika ia kembali ke Kanaan dari Haran (Kejadian 34-35), dan juga merupakan situs-situs yang diduduki dalam kisah penaklukan Kanaan di bawah Yosua. Mengutip Cassuto, Ia berpendapat bahwa alasan dari penyebutan ini ialah:

"... to show that what happened to Abraham also happened to Jacob and then also to their descendants. This is to show that the conquest of the land had already been accomplished in a symbolic way in the times of the fathers, demonstrated by means of their building their altars and purchasing property. Thus it shows that in the deeds of the fathers there is a source of trust that the Lord has cared for them from the very start and that he will still remain trustworthy in the days of the descendants of the fathers later on." [John Sailhamer, "Genesis," in Expositor's Bible Commentary 2 (Gen. Ed. Frank E. Gaebelain; Grand Rapids: Zondervan, 1990), 113].

Mengingat tujuan ini, nampaknya tidak salah untuk berpikir bahwa, meski tidak tercatat di dalam Alkitab, kemungkinan Abraham juga membangun mezbah di tempat-tempat lain. 
33:20) dan Betel (Kejadian 35:1, 3, 7, 14), serta sekali mempersembahkan korban di Bersyeba (Kejadian 46:1). Dari catatancatatan ini, bisa disimpulkan bahwa konsep tempat ibadah pada masa praMosaik masih sangat sederhana, dalam arti belum ada tempat ibadah yang terorganisir dan berpindah-pindah.

\section{Fase Mosaik sampai Davidik}

Pada masa Musa terjadi perkembangan signifikan dalam konsep tempat ibadah bangsa Israel. Meski pada awalnya bentuk ibadah masih meneruskan pola ibadah pra-Mosaik (band. Keluaran 17:15; 18:12), pada zaman Musa terjadi dua perkembangan besar dalam konsep tempat ibadah bangsa Israel. Perkembangan besar pertama ialah dimulainya model tempat ibadah yang semi-permanen. Bila pada masa pra-mosaik, tempat ibadah kebanyakan bersifat temporer, mayoritas membangun di tempat tertentu, dan setelah itu ditinggalkan, maka kini tempat ibadah umat Allah bersifat sedikit lebih permanen. Wujud perkembangan ini ialah dibangunnya Kemah Suci sebagai lokasi ibadah utama mereka. Tujuan pembangunan ini sendiri tercatat jelas dalam Keluaran 25:8, yakni “ supaya Aku akan diam di tengah-tengah mereka.” Dengan kata lain, Tabernakel sebagai tempat ibadah umat Allah yang semi-permanen, di saat yang sama juga menjadi lambang kehadiran Yahweh di tengahtengah bangsa Israel.

Bukan hanya soal aspek semi-permanen, perkembangan besar ini juga mencakup sentralitas tempat ibadah tersebut. Bila di masa pramosaik, umat Allah bebas beribadah dan mempersembahkan korban di mana saja, maka pada masa Musa muncul batasan agar mereka beribadah di satu tempat saja. Dekrit ini jelas diungkapkan Musa dalam Ulangan 12. Di sana, Musa mulai dengan mengingatkan bangsa Israel agar kelak ketika mereka memasuki tanah perjanjian, mereka harus memusnahkan semua mezbah dan tugu berhala serta tiang-tiang maupun patung-patung berhala penduduk setempat (ayat 3). Penggunaan bentuk piel dalam ayat ini nampaknya mengindikasikan bahwa umat Israel harus benar-benar menghilangkan segala bentuk penyembahan berhala tersebut. 
Setelah larangan itu, Musa dua kali menegaskan agar bangsa Israel beribadah hanya di tempat yang Tuhan pilih untuk menegakkan namaNya (ayat $5-7 ; 10-11$ ). Pengulangan ini nampaknya menunjukkan betapa pentingnya perintah ini untuk ditaati bangsa Israel. Tujuan perintah ini makin diperjelas di ayat 13-14, yakni supaya bangsa Israel tidak mempersembahkan korban di sembarang tempat yang mereka lihat melainkan hanya di tempat yang Tuhan pilih. ${ }^{10}$ Meskipun ada sedikit perkecualian di ayat 21 , namun secara umum aturan ini menjadi perintah mendasar bagi seluruh bangsa Israel.

Singkatnya, perkembangan besar kedua yang muncul dalam konsep tempat ibadah bangsa Israel ialah sentralisasi tempat ibadah, atau adanya satu tempat ibadah saja bagi bangsa Israel. Kedua aspek ini terus bertahan hingga nanti pada masa Daud terjadi penegasan.

\section{Fase Davidik sampai Paska-Pembuangan}

Pada masa Daud dan sesudahnya juga terjadi dua perkembangan dalam konsep bangsa Israel mengenai tempat ibadah mereka. Perkembangan pertama, tentu saja, ide tempat ibadah yang lebih permanen. Meskipun pembangunan tempat ibadah permanen baru terlaksana pada masa Salomo, tetapi ide awal pendirian tempat ibadah yang demikian dicetuskan oleh Daud (2 Samuel 7:1-3; 1 Tawarikh 17:12). Bahkan Daudlah yang mempersiapkan mayoritas material dan sumber daya manusia untuk pembangunan Bait Allah tersebut (1 Tawarikh 22:2 dan seterusnya; 28:1-29:9).

10 Terkait dengan ayat 13-14 ini, Craigie menulis:

"There was also a danger, warned against in these verses, that the people might be tempted to offer their legitimate burnt offerings to the Lord in illegitimate places; the words every place that you see refer by implication to Canaanite religious sanctuaries (see v. 2), though they could also refer to any place not sanctified by the Lord's choice. Hence $v .14$ repeats emphatically the note of $v .5$, that the sacrifices could be offered only in the place chosen by God."

Lihat Peter C. Craigie, The Book of Deuteronomyeronomy (NICOT; Grand Rapids: Eerdmans, 1976), p.218. Penekanan asli. 
Perkembangan kedua ialah penegasan terhadap signifikansi satu tempat ibadah. Sejak Salomo mendirikan Bait Allah, maka konsep satu tempat ibadah bagi bangsa Israel makin diperkuat, sebab hanya di Bait Sucilah tempat yang Allah kuduskan bagi nama-Nya (band. 1 Raja-Raja 9:7). Penegasan ini makin terlihat jelas dalam dua hal. Pertama, rujukan yang cenderung bernada negatif terhadap raja-raja yang tidak memusnahkan bukit-bukit pengorbanan, meskipun secara umum mereka memiliki karakter hidup yang baik. Misalnya Asa (1 Raja-Raja 15:14 ), Yosafat (1 Raja-Raja 22:44), Yoas (2 Raja-Raja 12:3), Amazia (2 RajaRaja 14:4), Azarya (2 Raja-Raja 15:3), dan Yotam (2 Raja-Raja 15:35).

Beberapa orang menganggap bukit-bukit pengorbanan tersebut merupakan bukit-bukit pengorbanan bagi berhala, sehingga rujukan negatif tersebut dimaksudkan untuk mencela toleransi raja-raja tersebut terhadap penyembahan berhala yang masih di terjadi di kalangan bangsa Israel; bukan soal sentralitas tempat ibadah. Akan tetapi, pandangan demikian nampaknya tidak terlalu tepat, khususnya karena rujukan di 1 Raja-Raja 3:2 yang mengaitkan keberadaan bukit-bukit pengorbanan tersebut dengan belum adanya Bait Allah. Ayat ini jelas mengindikasikan bahwa bukit-bukit pengorbanan tersebut dibuat untuk penyembahan kepada Allah, bukan untuk penyembahan kepada berhala. Jadi, masalah dengan bukit-bukit pengorbanan ialah karena keberadaannya mengingkari perintah yang disampaikan melalui Musa, bahwa hanya boleh ada satu tempat ibadah. ${ }^{11}$

11 Senada dengan itu, R. D. Patterson and Hermann J. Austel menulis:

"The high places were a constant sore point in Israel, and the prophets of God frequently spoke out against them. There were two basic problems with them: (1) they detracted from the principle of the central sanctuary (Deuteronomy 12:1-14); and (2) since worship at high places was a Canaanite custom, syncretism was not only a very real danger but an all too common occurrence. Israel was specifically forbidden to utilize pagan high places and altars (Deuteronomy 12:2-4, 13), and as soon as God had established his people in the Land of Promise, they were to worship at a sanctuary in the place appointed by God."

Lihat R. D. Patterson and Hermann J. Austel, “1 \& 2 Kings,” Expositor's Bible Commentary 4 (Gen.ed. Frank E. Gaebelein; Grand Rapids:Zondervan, 1988), p.43. Penekanan ditambahkan. 
Penegasan kedua ialah munculnya teologi doa dengan berpusat (1 Raja-Raja 8:31-43) dan berkiblat (1 Raja-Raja 8:44-45; 48-49) pada Bait Allah di dalam doa Salomo. Pada masa selanjutnya, aspek ini nampaknya mengakar lebih kuat dalam diri bangsa Yehuda. Misalnya, praktik doa kiblat yang dilakukan Daniel di dalam Daniel 6:11, jelas sangat dipengaruhi konsep bahwa hanya ada satu tempat ibadah yang benar, simbol kehadiran Allah yang sah, yakni di Yerusalem. Karena itulah, ia berdoa menghadap ke Yerusalem.

\section{Konklusi}

Dari pembahasan singkat di atas, terlihat bahwa konsep tempat ibadah di dalam Perjanjian Lama, mulai dengan bentuk yang masih sederhana, yakni sporadis dan tidak permanen, menuju ke bentuk yang semi permanen dan terpusat di masa Musa, hingga akhirnya mencapai bentuk yang permanen dan sangat terpusat di masa Daud dan sesudahnya. Satu aspek penting yang perlu diperhatikan di sini ialah sentralitas tempat ibadah tersebut. Hanya ada satu tempat ibadah di tempat yang Tuhan tentukan, tidak ada yang lain! Signifikansi ini terlihat jelas pada masa kemudian ketika Zerubabel dan Herodes membangun kembali Bait Allah di situs yang sama dengan tempat Salomo membangun Bait Allah pertama kali. Sementara catatan di Kisah Rasul 2 mengenai orang-orang Yahudi yang berkumpul di Yerusalem pada perayaan Pentakosta nampaknya mengindikasikan bahwa konsep sentralitas tempat ibadah ini bertahan, setidaknya, hingga masa hidup Tuhan Yesus dan para rasul.

\section{INJIL YOHANES: YESUS SEBAGAI PENGGENAP}

Setelah memahami bagaimana perkembangan konsep tempat ibadah di dalam Perjanjian Lama, penulis akan memaparkan bagaimana Injil Yohanes menampilkan Yesus sebagai penggenap tempat ibadah tersebut. Di dalam menunjukkan Yesus sebagai penggenap tempat ibadah Perjanjian Lama, ada empat teks kunci yang digunakan Yohanes di dalam Injilnya. 


\section{Yohanes 1:14}

Teks pertama ialah Yohanes 1:14, “Firman itu telah menjadi manusia, dan diam di antara kita, dan kita telah melihat kemuliaan-Nya, yaitu kemuliaan yang diberikan kepada-Nya sebagai Anak Tunggal Bapa, penuh kasih karunia dan kebenaran." Menarik dicatat bahwa kata " diam" atau " tinggal " yang digunakan Yohanes di sana bukan kata yang umum digunakan, yakni $\mu \epsilon \nu \omega$. Di sini Yohanes menggunakan kata kerja Ł́ $\sigma \kappa \eta ́ \nu \omega \sigma \epsilon \nu$ yang hanya muncul dua kali di dalam Alkitab, yakni ayat ini dan satu lagi di dalam Kitab Wahyu. Brown mencatat bahwa secara etimologis, kata ini terkait dengan kata $\sigma \kappa \eta \nu \eta$ (tenda) dan secara literal berarti "memasang sebuah tenda"" atau "bertabernakel."

Penggunaan kata ini jelas mengingatkan pembaca Injil Yohanes pada kemah peribadatan bangsa Israel di Perjanjian Lama. ${ }^{13}$ Ridderbos mengatakan bahwa motif dasar penggunaan kata kerja ini ialah tabernakel di padang belantara di mana kehadiran Allah di Israel dan kemuliaan-Nya dinyatakan. ${ }^{14}$ Morris menambahkan, “ That John wants us to recall God's presence in the tabernacle in the wilderness seems clear from the immediate reference to "glory," for glory was associated with the tabernacle."15 Melalui penggunaan kata ini, Yohanes ingin menunjukkan kepada pembacanya bahwa Yesus adalah anti-type dari type tabernakel di Perjanjian Lama: sebagaimana dahulu Allah menyatakan kemuliaan kehadiran-Nya melalui tabernakel, maka kini Allah menyatakan kemuliaan-Nya dengan cara yang lebih personal, yakni melalui AnakNya yang berkemah di tengah-tengah manusia.

Raymond E. Brown, The Gospel According to John I-XII (AB; New Haven: Yale, 2008), p.13.

13 Lihat Carson, John, p.127.

14 Herman Ridderbos, Injil Yohanes: Suatu Tafsiran Theologis (trans. Lanna Wahyuni; Surabaya: Momentum, 2012), h.55.

15 Leon Morris, The Gospel According to John (NICNT; Grand Rapids: Eerdmans, 1995), p.91. 


\section{Yohanes 1:51}

Teks kedua yang perlu disimak adalah Yohanes 1:51. Bagian ini termasuk dalam bagian percakapan Yesus dengan Natanel. Dalam bacaan ini dikisahkan bahwa Yesus menjawab keraguan Natanel di ayat 46 dengan menunjukkan pengetahuan supranatural-Nya (ayat 47-48). Kemudian meresponi kepercayaan Natanel, Yesus mengatakan bahwa murid-murid akan melihat hal-hal yang lebih besar (ayat 50). Salah satu wujudnya ialah: "....sesungguhnya engkau (kalian) akan melihat langit terbuka dan malaikat-malaikat Allah turun naik kepada Anak Manusia" (ayat 51). ${ }^{16}$

Jawaban yang Yesus berikan ini mengingatkan pembaca kepada peristiwa Yakub di Betel (Kejadian 28:10-22). Di sana, Yakub bermimpi melihat sebuah tangga yang ujungnya sampai di langit dan malaikat Allah naik turun $^{17}$ di tangga itu. Ungkapan "malaikat-malaikat Allah naik turun" jelas menjadi penanda yang menunjukkan bahwa Yesus memang sedang merujuk pada peristiwa Yakub di Betel tersebut. ${ }^{18}$

Meski demikian, ada dua perbedaan antara ucapan Yesus dan mimpi Yakub di Betel. Pertama, di dalam mimpi Yakub tidak ada catatan soal "langit terbuka," sebuah gambaran khas apokaliptik Yahudi, yang berbicara tentang penerimaan visi dari dunia yang berbeda. ${ }^{19}$ Penambahan ini nampaknya dipengaruhi oleh kemunculan gelar "Anak Manusia" di ayat ini. Kostenberger menulis bahwa gambaran apokaliptik tentang "langit terbuka" memang beberapa kali dikaitkan dengan sebutan "Anak Manusia." ${ }^{20}$ Kedua, di dalam mimpi Yakub, malaikat-malaikat

\footnotetext{
16 Carson dengan tepat menuliskan: "Although Jesus is adressing Nathanael, the "you" to whom he promises the vision of $v .51$ is plural; the vision is probably for all the disciples, and by extension, for those who would follow them." (Carson, John, p.163).

17 Terjemahan LAI "turun naik" tidak tepat, sebab kata "naik" diletakkan lebih dulu. Morris mengatakan, "In both the angels are saidn to ascend first, which may imply their presence on earth already." (Morris, John, p.149).

18 Morris menulis, "the ascent and descent of angels seems to be a reference to the vision of Jacob" (Ibid).

19 Kostenberger, John, p.85.

20 Ibid., p.86.
} 
tersebut naik turun di tangga, sementara di dalam ucapan Yesus, malaikat-malaikat tersebut naik turun menuju kepada Anak Manusia. ${ }^{21}$ Jadi, di sini, Yesus digambarkan menjadi penghubung antara surga dan bumi.

Lantas apa maksud Yohanes memasukkan bagian ini? Dengan menyertakan ucapan ini, Yohanes sedang menunjukkan bahwa Yesus adalah Betel (Rumah Allah) yang baru. ${ }^{22}$ Bila dahulu Allah menyatakan diri-Nya di Betel, maka kini Allah tidak lagi menyatakan diri-Nya di sana, melainkan di dalam Yesus. ${ }^{23}$ Yesuslah yang kini menjadi penghubung antara surga dan bumi, dan melalui Dialah hal-hal surgawi akan disingkapkan.

\section{Yohanes 2:19-21}

Teks ketiga yang perlu diperhatikan ialah Yohanes 2:19-21. Teks ini merupakan bagian dari episode penyucian yang dilakukan Yesus terhadap bait Allah. Ketika orang-orang Yahudi menantang otoritas Yesus dengan meminta tanda kepada-Nya (ayat 18), Ia menjawab, "Rombak Bait Allah ini, dan dalam tiga hari Aku akan mendirikannya kembali" (ayat 19). Yohanes kemudian menampilkan sebuah misunderstanding ${ }^{24}$ dari orang-orang Yahudi mengenai pernyataan Yesus tersebut ketika mereka berkata, "Empat puluh enam tahun orang mendirikan Bait Allah ini dan Engkau dapat membangunnya dalam tiga hari?" (ayat 20). Yohanes lantas memberikan komentar teologis bahwa sebenarnya yang dimaksudkan Yesus dengan Bait Allah ialah tubuh-Nya sendiri (ayat 21).

Para sarjana tidak sependapat mengenai kaitan kisah ini dengan catatan penyucian di Sinoptik yang terjadi di akhir pelayanan Yesus. Beberapa sarjana (mis. Blomberg, ${ }^{25}$ Carson, ${ }^{26}$ Morris $^{27}$ ) beranggapan

\footnotetext{
Ungkapan "Anak Manusia" di sini merupakan interlokutor untuk Yesus sendiri.

Kostenberger, John, p.86.

Carson, John, p.164.

Untuk memahami misunderstanding dalam Injil Yohanes, lihat D.A. Carson,

"Understanding Misunderstandings in the Fourth Gospel," TynB 33 (1982): p.59-91.

25 Craig L. Blomberg, The Historical Reliability of the Gospel ( $2^{\text {nd }}$ edition; Downers

Grove: IVP, 2007), p.216-9.
} 
bahwa Yesus menyucikan Bait Allah setidaknya sebanyak dua kali, yakni di awal pelayanan-Nya (sebagaimana dicatat Yohanes) dan di akhir pelayanan-Nya (sebagaimana dicatat Injil Sinoptik). Akan tetapi, menimbang beberapa hal nampaknya lebih tepat memaknai bahwa Yesus menyucikan bait Allah hanya sekali, yakni sesuai dengan catatan Sinoptik, menjelang akhir pelayanan-Nya. ${ }^{28}$ Pertama, ini sesuai dengan natur Yohanes yang lebih teologis ketimbang kronologis dibanding Injil Sinoptik. ${ }^{29}$ Kedua, meski memang ada kemungkinan Yesus melakukan atau mengajarkan suatu hal beberapa kali, sehingga menghasilkan catatan yang berbeda. Namun, tidak berarti bahwa semua catatan yang berbeda menunjukkan bahwa hal tersebut dilakukan Yesus beberapa kali. Catatan penyangkalan Petrus di dalam Injil Yohanes dan Injil Sinoptik juga tidak persis sama, namun tidak berarti bahwa Petrus menyangkal lebih dari tiga kali. Ketiga, tindakan Yesus menyucikan Bait Allah tentunya merupakan tindakan yang amat serius bagi pemimpin agama Yahudi. Jadi, nampaknya hampir mustahil bila mereka membiarkan peristiwa tersebut terjadi sampai dua kali.

Lantas mengapa Yohanes menempatkan kisah penyucian ini di awal pelayanan Yesus? Nampaknya, lagi-lagi Yohanes memiliki alasan teologis di baliknya. Yohanes kembali ingin menampilkan Yesus sebagai penggenap berbagai ritual keagamaan di dalam agama Yahudi. Setelah menampilkan Yesus sebagai penggenap tabernakel (1:14), ritual korban (1:29-34), dan ritual penyucian (2:1-11), kini Yohanes kembali menampilkan Yesus sebagai penggenap tempat ibadah: Yesus adalah Bait Allah sebenarnya. Melalui tipologi Bait Allah dan tubuh-Nya, Yohanes kembali ingin menegaskan bahwa Yesuslah lambang kemuliaan dan kehadiran Allah di tengah-tengah umat manusia, dan karenanya, patut menjadi pusat penyembahan. Atau, seperti yang dikatakan Carson,

\footnotetext{
Carson, John, p.177-8.

Morris, John, p.166.

Band. Brown, John I-XII, p.117.

29 Ini tidak berarti menyatakan bahwa Injil Yohanes tidak reliabel secara historis. Apa yang penulis maksud ialah bahwa Yohanes kerapkali menyusun peristiwa-peristiwa historis tersebut lebih tidak kronologis demi tujuan teologis yang Ia ingin sampaikan.
} 
"Therefore it is the human body of Jesus that uniquely manifests the Father, and becomes the focal point of the manifestation of God to man, the living abode of God on earth, the fulfilment of all the temple meant, and the centre of all true worship (over against all other claims of 'holy space', 4:20-24). In this 'temple' the ultimate sacrifice would take place; within three days of death and burial, Jesus Christ, the true temple, would rise from the dead. ${ }^{, 30}$

\section{Yohanes 4:20-24}

Ketiga teks penggenapan tadi berpuncak pada teks keempat yang ada dalam Yohanes 4:20-24. Setelah seorang perempuan Samaria berbincang dengan Yesus perihal kehidupan pribadinya, ia akhirnya mengakui bahwa Yesus ialah seorang nabi (ayat 19). Pengakuan tersebut nampaknya membuat perempuan tersebut tertarik membawa perdebatan besar antara bangsa Yahudi dan orang Samaria (perihal manakah tempat ibadah yang paling benar) ke dalam diskusinya dengan Yesus (ayat 20). Pada dasarnya kedua bangsa ini percaya bahwa Allah memerintahkan mereka untuk beribadah di tempat yang Ia tentukan (band. Ulangan 12:5). Namun, perbedaan tempat muncul karena orang-orang Samaria hanya menerima Taurat sebagai Kitab Suci mereka.

Karena orang Yahudi menerima keseluruhan Kanon Ibrani, maka mereka beranggapan bahwa Yerusalem ialah tempat yang Allah pilih untuk menegakkan nama-Nya. Daud memilih Yerusalem sebagai tempat didirikannya Bait Allah, dan Allah menyetujui niatnya itu ketika Ia menyertai pembangunan Bait Allah pada masa Salomo. Namun, orang Samaria tidak menerima keyakinan tersebut. Alih-alih menerima Yerusalem sebagai pusat ibadah, mereka justru mencari tempat suci lain di dalam Taurat. Mereka menemukan bahwa Sikhem, yang terlihat dari bawah Gunung Gerizim, adalah tempat pertama Abraham membangun mezbah ketika ia memasuki tanah perjanjian (Kejadian 12:6). Di Gunung

30 Carson, John, p.182. Penekanan ditambahkan. Band. juga kutipan Kostenberger terhadap Barret, "The human body of Jesus was the place where a unique manifestation of God took place and consequently became the only true Temple, the only centre of true worship." Lihat Andreas J. Kostenberger, John (BECNT; Grand Rapids: Baker, 2004), p.110. 
Gerizim pula berkat diucapkan (Ulangan 11:29-30; 27:2-7). Bahkan berdasarkan Kitab Suci mereka, orang Samaria memercayai bahwa Sepuluh Perintah Allah punya kaitan yang erat dengan Gunung Gerizim. ${ }^{31}$ Ini semua membuat mereka akhirnya memilih Gunung Gerizim sebagai tempat suci di mana mereka menyembah Allah.

Jawaban Yesus di ayat 21 mengindikasikan bahwa pertanyaan soal legalitas tempat ibadah tersebut bukanlah pertanyaan yang relevan bagiNya. Meskipun Ia mengakui superioritas bangsa Yahudi di ayat 22, tetapi pada akhirnya Yesus menjelaskan datangnya sebuah babak baru dalam konsep tempat ibadah Alkitabiah: nilai sebuah ibadah tidak lagi ditentukan dari " di mana seseorang menyembah" tetapi " bagaimana seseorang itu menyembah." Di ayat 23-24 Yesus berbicara bahwa penyembah yang benar menyembah Allah di dalam roh dan kebenaran.

Para sarjana memberikan beragam pendapat mengenai arti roh dan kebenaran dalam ucapan Yesus ini. Ridderbos misalnya berpendapat bahwa roh dan kebenaran menunjuk kepada persekutuan yang dibangun dalam kuasa-Nya yang menciptakan kehidupan dan memberi kehidupan, yang memimpin kepada kepenuhan karunia Allah (band. 1:16) yang tidak lagi diperantarai oleh segala macam kesementaraan dan simbolis, tetapi oleh Roh Allah sendiri. ${ }^{32}$ Sementara Morris menulis,

"It is not likely that "spirit" here means the Holy Spirit (though the Spirit does help our worship, Roma 8:26ff). It is the human spirit that is in mind. One must worship, not simply outwardly by being in the right place and taking up the right attitude, but in one's spirit ... The combination "spirit and truth" points to the need for complete sincerity and complete reality in our approach to God. There is an important point in the concluding statement that the Father seeks such to be his worshipers. "33

Carson, John, p.222.

Ridderbos, Injil Yohanes, h.175.

Morris, John, p. 239. 
Penjelasan yang lebih tepat konteks diberikan oleh Carson dan Kostenberger. ${ }^{34}$ Mereka berpendapat bahwa maksud Yesus dalam frasa " menyembah dalam roh dan kebenaran" ialah penyembahan yang tidak terikat pada tempat kudus tertentu - seperti halnya kehadiran Allah yang adalah roh, yang tidak terikat oleh tempat tertentu - dan berfokus pada Allah yang memperkenalkan diri-Nya secara penuh di dalam Anak-Nya, Sang Kebenaran (Yohanes 14:6). Jadi, ketika perempuan tersebut mempertanyakan di situs manakah sebuah penyembahan dianggap legal, Yesus menyatakan bahwa legalitas penyembahan tidak lagi didasarkan pada lokasi - sebab Allah yang roh itu tidak dikurung oleh lokasi - tetapi pada sikap hati yang berfokus pada Yesus, Sang Kebenaran.

\section{SIMPULAN DAN IMPLIKASI}

Yohanes menunjukkan dalam Injilnya bahwa konsep tempat ibadah bangsa Israel telah menemukan penggenapannya di dalam diri Yesus: Yesus adalah Sang Tabernakel sejati (Yohanes 1:14), Betel sejati (Yohanes 1:51), dan Bait Allah sejati (Yohanes 2:19-21). Melalui penggenapan ini, Yesus membawa babak baru dalam konsep ibadah alkitabiah. Nilai legalitas ibadah tidak lagi ditentukan berdasarkan tempat di mana seseorang menyembah seperti yang diyakini bangsa Israel dan dipertanyakan seorang perempuan Samaria dalam Yohanes 4. Allah adalah roh yang tidak dibatasi oleh tempat, oleh sebab itu penyembahan kepada-Nya juga seharusnya tidak dibatasi oleh batas-batas spasial, seolah tempat yang satu lebih kudus daripada tempat yang lain. Sebaliknya, nilai sebuah ibadah ditentukan dari bagaimana orang itu menyembah: apakah ia menyembah dengan berfokus pada Allah yang dikenal melalui Yesus atau tidak? Ibadah baru memiliki nilai ketika ibadah tersebut berfokus pada Yesus, Sang Kebenaran Allah.

Mengingat tujuan besar Injil Yohanes yang bersifat misional (band. Yohanes 20:30-31), bagi pembaca pertama Injil Yohanes, penggenapan ini nampaknya menjadi salah satu bagian dari upaya besar Yohanes mempersuasi orang-orang non-Kristen (khususnya Yahudi diaspora dan

34 Carson, John, p.224-6; Kostenberger, John, p.156. 
orang-orang non-Yahudi yang tertarik dengan Yudaisme) bahwa orangorang Kristenlah penerus ibadah yang sejati yang dimulai Allah sejak jaman Perjanjian Lama. Ini sama dengan apa yang diungkapkan Kostenberger, bahwa 'John's emphasis on Jesus' replacement of the temple and Jewish feast probably represent an effort to exploit the temple's destruction evangelistically in an effort to reach diaspora Jews and Gentiles attracted to Judasim." 35

Dari pembahasan ini, setidaknya ada empat implikasi yang bisa direnungkan bagi kekristenan kontemporer:

1. Karena menyembah dalam roh dan kebenaran berbicara tentang penyembahan yang tanpa batas dan berfokus pada Yesus, maka pandangan kelompok Pentakosta-Karismatik yang mengaitkan frasa ini sebagai dukungan bagi pola ibadah dengan berbahasa roh atau bentuk-bentuk " ekstase roh" lainnya jelas tidak mendapat dukungan dari teks ini.

2. Kegiatan kelompok Kristen tertentu yang mengadakan baptis ulang, pemberkatan nikah ulang ataupun ibadah khusus dalam ziarah iman di tanah Israel pada dasarnya bukan sikap yang alkitabiah. Sikap tersebut mengesankan seolah ritual di tanah Israel lebih bernilai dan diperkenan Tuhan ketimbang ritual ibadah di gereja lokal. Dengan kata lain, sikap demikian pada dasarnya menyangkali penggenapan Yesus terhadap konsep tempat ibadah Perjanjian Lama.

3. Perlukah tempat ibadah fisik? Tentu saja, sebab orang-orang Kristen sendiri masih terikat pada batas-batas ruang. Namun demikian, orang-orang Kristen perlu berhati-hati terhadap pengultusan tempat atau ruangan tertentu. Seolah ibadah di tempat tertentu lebih suci dan berkenan kepada Allah dibanding tempat lainnya. Sekali lagi, nilai ibadah yang sejati tidak lagi terletak pada "di mana" tetapi pada "bagaimana."

4. Karena nilai ibadah terletak pada fokusnya, maka seharusnya gereja menjadikan semua elemen kegerejaan sebagai penolong jemaat

35 Andreas J. Kostenberger, Encountering John: The Gosple in Historical, Literary, and Theological Perspective (Kindle version; Grand Rapids: Baker, 1999), loc. 386. 
berfokus pada Yesus. Meskipun ibadah bukanlah upacara kaku, tetapi ibadah juga bukan wahana entertainment jemaat. Karena itu, gereja tidak seharusnya berfokus pada kepuasan jemaat, tetapi bagaimana menolong jemaat berfokus pada Yesus dan mengalami kasih-Nya melalui tiap-tiap ibadah yang diselenggarakan. Ibadah hanya bernilai bila fokus ibadah ialah Yesus. Maka, sebuah ibadah tanpa Yesus, semegah dan semeriah serta sehebat apapun, tetap tidak ada nilainya.

\section{KEPUSTAKAAN}

Blomberg, Craig L., The Historical Reliability of the Gospel, $2^{\text {nd }}$ edition; Downers Grove: IVP, 2007.

Brown, Raymond E., The Gospel According to John I-XII, AB; New Haven: Yale, 2008.

Carson, D.A., The Gospel Accoding to John, PNTC; Grand Rapids: Eerdmans, 1991.

, Kesalahan-Kesalahan Eksegetis, Terjemahan Lanna Wahyuni; Surabaya: Momentum, 2009.

, "Understanding Misunderstandings in the Fourth Gospel," TynB 33, 1982 : 59-91.

Craigie, Peter C., The Book of Deuteronomyeronomy, NICOT; Grand Rapids: Eerdmans, 1976.

Handoko, Yakub Tri, Diktat Kuliah Injil Yohanes, Pacet: STTIAA, 2005.

Kostenberger, Andreas J., Encountering John: The Gosple in Historical, Literary, and Theological Perspective, Kindle version; Grand Rapids: Baker, 1999. , John, BECNT; Grand Rapids: Baker, 2004. 
150 Yesus Sebagai Penggenap Tempat Ibadah dalam Injil Yohanes

Patterson, R. D. and Hermann J. Austel, “1 \& 2 Kings," Expositor's Bible Commentary 4, Gen.ed. Frank E. Gaebelein; Grand Rapids: Zondervan, 1988.

Morris, Leon, The Gospel According to John, NICNT; Grand Rapids: Eerdmans, 1995.

Ridderbos, Herman, Injil Yohanes: Suatu Tafsiran Theologis, Terjemahan Lanna Wahyuni; Surabaya: Momentum, 2012.

Sandmel, Samuel, "Parallelomania," JBL 81, 1962 : 2-13

Sailhamer, John H., "Genesis," in Expositor's Bible Commentary 2, Gen.Ed. Frank E. Gaebelein; Grand Rapids: Zondervan, 1990.

Wenham, Gordon J., Genesis 1-15, WBC; Dallas: Word, 1987. 